\section{The buried hybrid mattress suture: A novel technique}

Sir,

Tissue approximation techniques have evolved from employing insect claws and linen glue strips. ${ }^{[1]}$ Surgical aims for suturing are well known. Patient characteristics, suturing materials and techniques, added to consideration of duration, anatomical zones, function, and aesthesis decide final outcomes. ${ }^{[2]}$ Despite advent of different technologies and methods, hand suturing techniques remain unparalleled in versatility.

The simple interrupted, continuous, vertical or horizontal mattress sutures, all have their utilities and drawbacks. The hybrid mattress suture judiciously balances the pros and cons of vertical and horizontal mattress suturing and is executed with speed. ${ }^{[3]}$ Wu et al. employ a combination of vertical and horizontal mattress on opposite sides of the defect, a technique suited to closing unequal size margins. ${ }^{[4]}$

We have devised a hybrid technique of vertical and horizontal mattress suturing as a buried variant.

\section{TECHNIQUE}

A demonstrative model made of silicon sheets placed in step form is illustrated for clarity of depth and obliquity of suture course. The needle is held obliquely along the long axis of the wound. It is inserted from the deep surface of the flap $1-2 \mathrm{~cm}$ away from the incision apex and 1-2 $\mathrm{cm}$ lateral to the cut edge. The needle moves obliquely through the tissue towards the incision apex and brings the suture from deep subcutaneous to superficial dermis and from 1 to $2 \mathrm{~cm}$ lateral entry in tissues to medial cut edge of the wound. The needle exits subepidermally near the wound apex [Figure 1]. The suture returns from the opposite edge as a reverse mirror image to exit at the same depth and distance on the opposite wound edge as the entry site [Figure 2]. We employ absorbable sutures on reverse cutting needles, the sizes being dictated by tissue thickness.

On tying the knot, the dermis and epidermis oppose with accuracy towards the apex where the suture is dermal. Deeper tissues approximate well with dead space obliteration at the site of buried knot where the needle is entering and exiting [Figure 3]. The closed wound edge resembles a downward slope from wound edge distally. The second interrupted hybrid mattress suture is similarly started at a more distal location from wound apex with the needle exiting subepidermally on top of the earlier deeper suture and knot. Progressing interrupted suturing leads to wound closure [Figure 4].

Oblique insertion of the needle along with the long wound axis allows for easy suturing in constrained spaces. A single hybrid buried suture brings two depths (deep fascial/subcutaneous and dermal layers) of tissues together across a wider length than interrupted stitches achieving deep dead space obliteration and accurate epidermal alignment. Wound edge vascularity remains uncompromised while ensuring haemostasis. The closure 


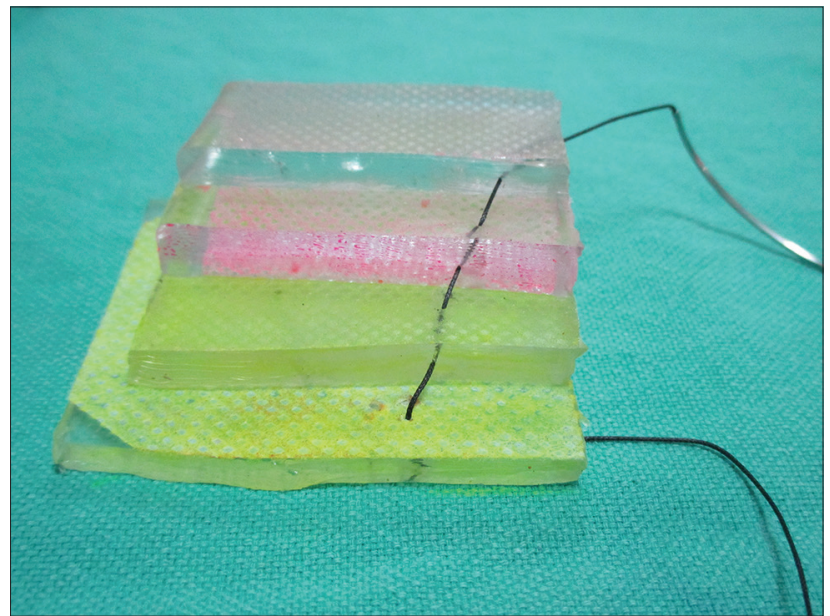

Figure 1: Needle inserted deep subcutaneously and passed towards wound apex, suture moving from deeper to superficial layers and lateral to medial to exit at the dermal level

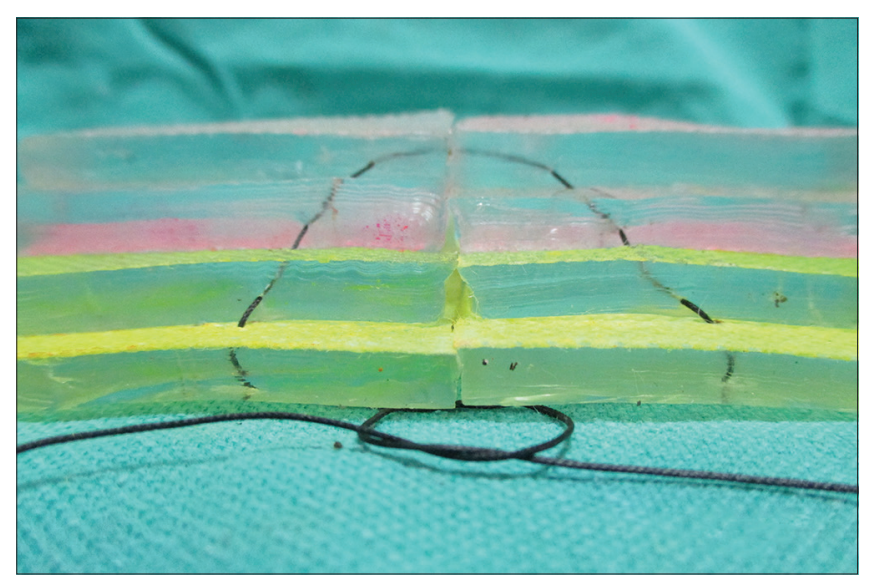

Figure 3: End on view of tied suture

is air and waterproof, and we have been routinely using it with suction drains where indicated. There are no suture track marks and no removal is needed.

We routinely employ hybrid sutures in skin closure or flap inset across diverse regions of variable skin thickness with success. The technique is easily grasped on demonstration and proficiency reached after a few cases. We feel that hybrid buried mattress suturing has potential for application in various situations and may prove to be a useful addition to existing suturing techniques.

\section{Financial support and sponsorship} Nil.

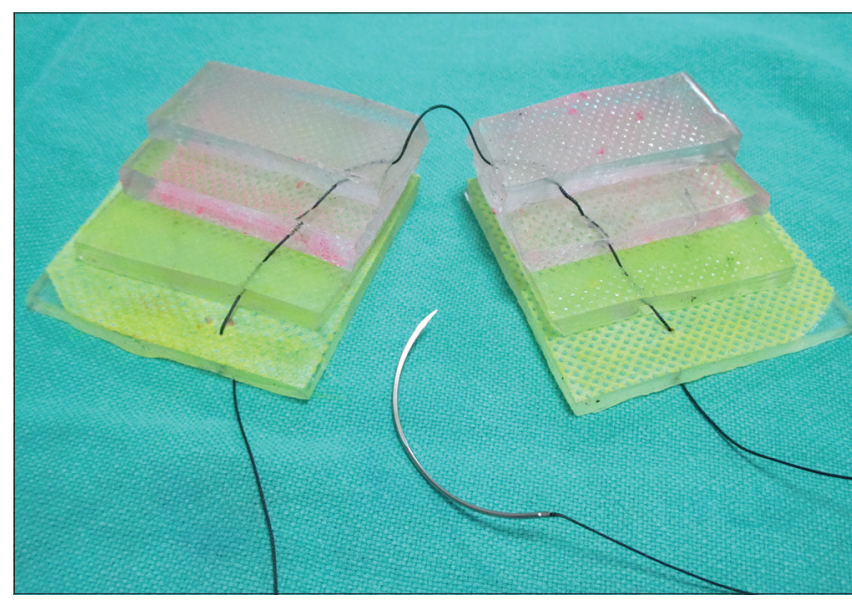

Figure 2: Completed suture before knotting, showing depth and obliquity

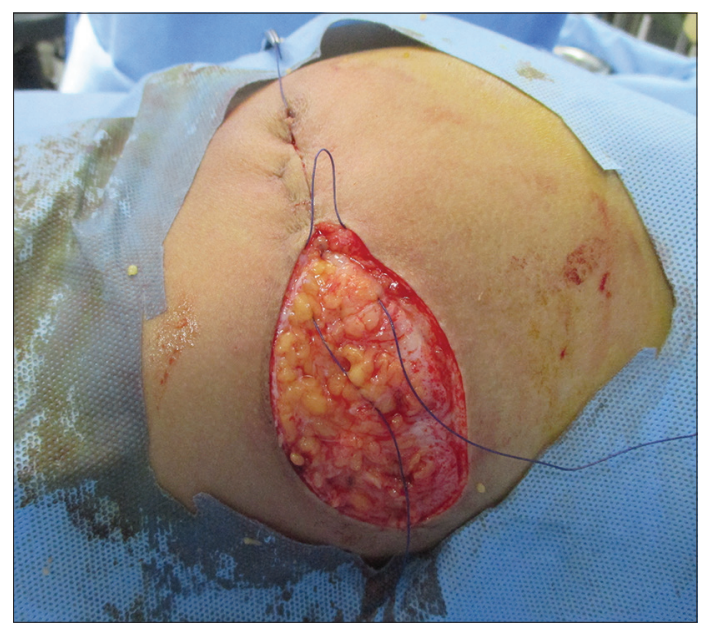

Figure 4: Sequential buried hybrid mattress suturing in progress

\section{Conflicts of interest}

There are no conflicts of interest.

Brig Sandeep Mehrotra, Megha Sharma

Department of Plastic Surgery, Army Hospital Research and Referral, New Delhi, India

Address for correspondence: Dr. Megha Sharma, Department of Plastic Surgery, Army Hospital Research and Referral, New Delhi, India.

\section{REFERENCES}

E-mail:meghauma@gmail.com

1. Samhita Samhita. Vol. 3. Translated by Bhishagratna KL. Varanasi, India: Chowkhamba Sanskrit Series Office; 1907- 
1911, 1963. p. $17,304,456,519$.

2. Parsons RW. Scar prognosis. Clin Plast Surg 1977;4:181-6.

3. Hoffman MD, Bielinski KB. Surgical pearl: The hybrid mattress suture. J Am Acad Dermatol 1997;36:773-4.

4. Wu W, Chavez-Frazier A, Migden M, Nguyen T. The buried half horizontal, half vertical mattress suture: A novel technique for wound edges of unequal lengths. Dermatol Surg 2016;42:1391-3.

This is an open access journal, and articles are distributed under the terms of the Creative Commons Attribution-NonCommercial-ShareAlike 4.0 License, which allows others to remix, tweak, and build upon the work non-commercially, as long as appropriate credit is given and the new creations are licensed under the identical terms.

\begin{tabular}{|l|l|}
\hline \multicolumn{2}{|c|}{ Access this article online } \\
\hline Quick Response Code: & Website: \\
\hline
\end{tabular}

How to cite this article: Mehrotra BS, Sharma M. The buried hybrid mattress suture: A novel technique. Indian J Plast Surg 2018;51:332-4.

() 2019 Indian Journal of Plastic Surgery | Published by Wolters Kluwer - Medknow 